\title{
MICROTREMOR RECORDING TECHNIQUES
}

\author{
I.M. Parton* and P.W. Taylor**
}

\section{SYNOPSIS}

For some years seismologists and engineers have been recording and measuring microtremors. In this paper a review of earlier micotremor investigations is presented and microtremor recording apparatus developed at Auckland University Engineering School is described.

Two distinct methods of recording have been developed. One uses a conventional low-cost tape recorder operating at reduced speed to record the low frequency signals. The other uses a frequency modulation methods and a high quality instrumentation tape recorder to accurately record signal levels.

This paper is the first of a series of three. In the second, method of analysing microtremor records, with particular emphasis on their frequency content will be presented, while in the last of the series the application of microtremor measurement to the design of earthquake resistant structures will be critically examined.

\section{INTRODUCTION}

In this, and a companion paper entitled "Analysis of Microtremor Records" are described the equipment and methods developed and used at the Auckland University School of Engineering to study the characteristics of microtremors and their relationship to subsurface conditions. In a third paper entitled "Applications of Microtremor Measurements to Earthquake Engineering" it will be shown that microtremors recorded at the ground surface do reflect subsoil conditions. However, as yet a relationship has not been developed which enables these measurements to be applied directly to earthquake resistant design of structures.

\section{THE NATURE OF MICROTREMORS}

Microtremors may be defined as 'continuous small ground vibrations resulting from uncontrolled natural or artificial excitation'.

Kanai and Tanaka (1) report that the amplitude of these vibrations is in the range 0.1 to $1 \mu \mathrm{m}$ while the frequency of the motion may be 0.5 to $20 \mathrm{~Hz}$ or more. Thus any seismograph with a magnification exceeding 1000 times will be capable of recording microtremors.

As the source of excitation of microtremors is largely derived from traffic and industrial activity, there is a distinct diurnal variation

* Ministry of Works, Wellington.

** Professor of Civil Engineering, University of Auckland.

Bulletin of the N.Z. Society for Earthquake Engineering, Vol. 5, No. 2, June, '1973.

commensurate with human activity. Kanai et al (loc.cit.) and Wilson(2) found the general level to be greater during the day by a factor of about 10 to 20 times around city areas. Natural sources include wind effects, waves breaking on sea shores, etc.

Brune and Oliver (3) have published a survey of the literature dealing with the seismic noise of the earth's surface. Essentially these measurements are of 'non-cultural' vibrations; noise due to industrial activity, traffic, waterfalls, etc. was excluded from the study. They report a considerable increase in amplitude in the 4 to 8 second period range.

Whether or not the 4 to 8 second period range movements caused by earth tides, storms and atmospheric pressure variations should be included under the title 'microtremors' appears to be a matter of opinion. Brune and oliver include this group while other writers consider these to be a separate category.

At Auckland University the basic objective was to record any horizontal tremors in the frequency range 0.1 to $10 \mathrm{~Hz}$. The upper limit was later extended to $20 \mathrm{~Hz}$.

\section{REVIEW OF MICROTREMOR INVESTIGATIONS}

The foremost worker in microtremor investigations has been the Japanese seismologist $K$. Kanai. Prior to his systematic recording of microtremors at different sites, in an effort to characterize the dynamic properties of soils, little attention had been paid to recording microtremors, Early studies reported by Kanai et al (4), (5) were concerned mainly with the amplitudes of vibration, although, in 1908, a Japanese seismologist observed that the 'average' period at a particular site was constant.

Carder and Gilmore ${ }^{(6)}$ recorded microtremors at several locations in California. They reported that the nature of the ground influences the frequency and magnitude of the surface motion. Traffic or non-periodic impact sources would cause the ground to vibrate in one of its 'natural' modes. A marked difference in recording level between day and night conditions was observed.

Patterson (7) measured dominant ground periods from microtremor recordings and controlled frequency shaking tests. Successive recordings with sensing units at different locations showed a maximum amplitude in one direction and a definite minimum in the normal to that direction. This observation suggests that the wave motions generated were a uni-directional phenomenon such as plane polarized waves.

Wilson (2) conducted an extensive investiga- 
tion into the origin and nature of short period microseisms (microtremors). The diurnal variation in amplitude observed by Kanai was found to be almost entirely dependent on human activity. The effect of city activity was found to be negligible 2 kilometres or more from its outskirts. Traffic on nearby roads caused a considerable change in signal level.

Wilson considered that the geological structure of the ground has no effect on microtremors in the area investigated and concluded that the greater part of microtremors are surface waves from traffic, aircraft and machinery. Close to the source, body waves predominate but several hundred yards from the source surface waves are the predominant wave form. Generally their attenuation renders them insignificant at a distance of more than 3 kilometers from the source.

Aki ${ }^{(8)}$ recorded microtremor motions and computed the autocorrelation functions. Comparisons of these, with curves derived theoretically from the site geometry, enabled Aki to identify the horizontal motion as a Love wave and the vertical motion as a Rayleigh wave.

Akamatu (9) made tripartite recordings of microtremors and established that the recorded waves have the nature of surface waves being Rayleigh of Love waves or a combination of both. At every site investigated a dominant period of microtremors particular to that locality was observed, irrespective of the time of recording. While some Japanese seismologists have attributed this 'dominant period' effect to the multiple reflections of vertically incident shear waves, Akamatu has suggested that the period corresponding to the minimum group velocity of surface waves is apt to predominate and would give rise to a 'dominant period'.

Kawasumi and Shima ${ }^{(10)}$ recorded microtremors at several locations in the Japanese city of Kushiro. The subsoils consisted of sands, alluvium and compacted fill. Computed power spectra of the motions showed appreciable peaks at each locality, supporting the findings of other writers that, for any particular site, certain dominant periods of microtremors could be discerned which are characteristic of that site. A broad relationship was established between the thickness of the surface deposit and the dominant period, the thicker deposits being assoclated with the higher periods. They considered the surface disturbance to be the result of body (shear) waves in the surface layers.

Adams and orr (11) undertook a study to determine the relative levels of microtremors in different parts of Wellington City, as an aid to understanding the vibrational characteristics of different soil types. Their analysis was primarily concerned with amplitudes of the observed microtremors rather than the distribution of periods of vibration in the records. In general the areas associated with the lowest levels were found to be in the higher parts of the city on grewwacke rock, while in those areas where the highest levels were recorded there was geological evidence of some thickness of softer material.

Hatherton and orr (12) undertook a similar study in Gisborne City. They found that the levels recorded, with respect to an arbitrary reference level, could be roughly related to the thickness of sand and muds above the 'papa' basement.

\section{SUMMARY OF OTHER INVESTIGATIONS}

Generally most researchers and writers have shown that the characteristics of surface recorded microtremors do reflect subsoil conditions. When microtremors are recorded on deep soft deposits they generally exhibit longer 'dominant' periods. Microtremors recorded on harder deposits or on exposed bedrock show the shortest dominant periods.

Generally there are differing views as to the form of microtremor waves. Some Japanese seismologists believe them to be solely body (shear) waves whilst other investigators have shown them to be combinations of surface waves. There is evidence that surface recorded microtremors could be a combination of body and surface waves, the exact nature of the wave depending upon the characteristics of the source and the separation of the source and observer.

\section{DEVELOPMENT OF MICROTREMOR RECORDING METHODS}

Microtremor investigations were pioneered at Auckland University by Salt(13) who developed slow motion magnetic tape recording equipment specifically for recording microtremors. Salt had adopted an arbitrary frequency range of 0.1 - $10 \mathrm{~Hz}$. Later the upper frequency limit was raised to $20 \mathrm{~Hz}$. Unfortunately Salt's study proved inconclusive because the frequency analysis equipment available at that time lacked the required discrimination. Salt acknowledged that the analysis equipment may have been lacking in that aspect.

With previous knowledge of the difficulties involved in recording and analysing microtremors, two independent methods of recording and analysis were later developed. The first method was a direct recording system employing a slow motion tape recorder and a tape recorder operating at normal speeds, such as was used by Salt, to recover the signal. Frequency analysis was accomplished using an analog sweep frequency analyzer with a very narrow bandwidth.

The second method developed was a real time recording and analysis technique in which the low frequency seismometer signal modulated a $5 \mathrm{kHz}$ carrier wave. The modulated wave was recorded on magnetic tape. On replaying the tape the input signal was recovered by a demodulation process, digitized at intervals of under 0.01 second and punched onto paper tape. In this form the record is suited to analysis by a computer.

The first method, which has been termed the 'Direct Recording Method' was intended as a low cost recording system which could be set up and perhaps left to run unattended for several days. With such a system however, the recovered signal would be subject to amplitude inaccuracies due to dust or foreign matter on the tape or recording head. The second or 'Frequency Modulation Method' was intended as a system with high accuracy which could provide data suitable for analysis on a digital computer.

Both methods have been described in detail by Parton(15). The methods adopted, their characteristics, advantages and disadvantages are briefly outlined in the following 


\section{DETECTION OF MICROTREMORS}

The basic sensing element in both methods is the Willmore seismometer. This instrument is an earth tremor detecting unit in which a heavy permanent magnet is suspended on a frictionless mounting inside a weatherproof casing. Earth tremors are transmitted to the seismometer and a relative motion is set up between the magnet and the casing as it vibrates with the ground. The magnet moves only in the direction of the axis and in doing so generates an E.M.F. in a coil fixed to the casing, which is directly proportional to the relative velocity between the two. The instrument may be set to operate in the vertical or horizontal mode and has an adjustable natural period in the range 0.6 to 2.5 seconds.

To maintain a given degree of seismometer damping for a specific seismometer period setting it is necessary to connect a shunt resistance in the external seismometer circuit. A small control unit was constructed which enabled shunt resistances appropriate to a given range of seismometer periods to be switched in as required.

The Willmore seismometer has a nonlinear frequency characteristic. At periods greater than the natural period of the seismometer the response falls off. To overcome this a compensating filter was used which extended the period range up to 10 seconds. Another filter was used to remove mains hum and other high frequency noise. The signal was then fed to a high gain a.c. amplifier. Amplification in 10 $\mathrm{db}$ steps was available up to a maximum of $60 \mathrm{db}$.

\section{DIRECT RECORDING METHOD}

The signal was recorded directly on magnetic tape using a tape recorder which operated at very low speeds. An inexpensive (BSR) tape deck was used, and modified by replacing the driving motor by a miniature Philips synchronous motor and reduction gearbox. This is similar to the equipment used by Dibble(14). When the magnetic tape recorder is to be used in any application involving the precise measurement of signal levels or the recording of slowly varying signals it suffers from a number of disadvantages. The principal disadvantage is that the response falls off markedly below about $30 \mathrm{~Hz}$. This frequency selective characteristic places a lower limit on frequencies which can be recorded at normal tape speeds and makes impossible the reproduction of d.c. levels.

It is possible to record down to very low frequencies with a suitable choice of tape speed and/or tape head dimensions. As the nominal frequency range of most tape recorders is in the range $30 \mathrm{~Hz}$ to $20 \mathrm{kHz}$, to record a low frequency limit of $0.1 \mathrm{~Hz}$ a tape speed reduction of 300 times must be used to produce the same wavelengths on the tape. The signal wavelength on the tape, with respect to the recording head dimension, is the critical factor when recording. Typical tape speeds when recording were in the range of 0.3 to 1.2 $\mathrm{mm} / \mathrm{s}$. These were achieved by running the tape capstan arive through a reduction gearbox.

Because the output of the tape replay head is proportional to the rate of change of flux, and therefore to frequency, the tapes must be replayed at normal tape speeds to raise the signal level above amplifier noise level. Thus on replay the recorded frequencies are multiplied by the speed-up ratio, which is the ratio of playback speed: recording speed. Speed-up ratios of 292 to 1170 could be obtained with the equipment used. In this way the frequency range to be recorded $(0.1$ to $20 \mathrm{~Hz})$ is transformed to $29-5840 \mathrm{~Hz}$ at the lowest ratio or 117 to $23400 \mathrm{~Hz}$ at the highest. These transformed frequencies are within the range for commercially available audio frequency analysers. The method of analysis will be described in a subsequent paper.

The recording arrangement is shown schematically in Figure 1. Analysis of recorded tapes is described in the companion paper.

\section{FREQUENCY MODULATION METHOD}

Another method of overcoming frequency response problems is to use one of the carrier wave techniques. These permit the accurate recording and reproduction of a wide range of frequencies at normal tape speeds. The most common of these is the Frequency Modulation (FM) method. With this system a constant frequency carrier wave is modulated by the input signal and the modulated wave recorded. on replay the input signal may be recovered by band pass filtering or selecting a carrier frequency beyond the range of associated equipment.

The FM method developed used the same Willmore seismometer, recording correction filter and input amplifier as the direct recording method. However, the input signal then modulated a $5 \mathrm{kHz}$ carrier wave which was recorded on a high quality direct recording machine. The Nagra recorder used has a single-track tape, ensuring a high signal to noise ratio. Operated from internal batteries, it is portable yet has extremely good frequency characteristics and high accuracy of tape speed control, that is "wow" and "flutter"are very low. Although this system is similar to the operation of a conventional FM tape recorder, modulation in this case is done externally to the tape recorder.

The FM method described above was a comparatively cheap way of accurately recording signal levels and frequencies. FM tape recorders are generally available, but they are usually in a different price category from the instrumentation machine employed for this work. The tape speed used with the FM method was $95 \mathrm{~mm} / \mathrm{s}$. The input signal was recovered by low pass filtering. The general arrangement for recording is shown schematically in Figure 2. On playback (at the same speed used during recording) the record is digitised and the result punched on to paper tape at the rate of 110 points per second.

An overall system calibration, relating seismometer velocity to the digital output of the paper tape punch, was determined experimentally by mounting the seismometer on a shaking table operated over the frequency range of interest. The result is shown in Figure 3. Response is linear within $\pm 1 \mathrm{db}$ over the range of 0.2 to $15 \mathrm{~Hz}$. There is, however, some fall-off in response at the extremes of the desired range $(0.1$ to $20 \mathrm{~Hz})$. 
A description of the equipment used and principles involved in two methods of recording microtremors has been given. In the direct recording method, the microtremor observations are stored on tape in a form suitable as input to an audio frequency analyser. The equipment used in the frequency modulation method produces a digitised record on paper tape, suited to analysis by computer.

The methods of analysis, to determine frequency content of the microtremor records, will be described in a further paper to be presented in a future issue of this Bulletin.

\section{REFERENCES}

1. Kanai K. and Tanaka T. (1961). On Microtremors VIII. Bul1. Eq. Res. Inst. Tokyo Univ., Vol. 39, p 97.

2. Wilson C.D.V. (1953). The Origins and Nature of Microseisms in the Frequency Range 4 to $100 \mathrm{~Hz}$. Proc. Royal Soc. of London, Series A, Vol. 217, p 176.

3. Brune J. N. and Oliver J. (1959). The Seismic Noise of the Earth's Surface. Bull. Seismological Soc. of America, Vol. 49, pp. 349-353.

4. Kanai K., Tanaka T. and Osada K. (1954). Measurement of Microtremors I. Bull. Eq Res. Inst., Tokyo Univ., Vol. 32, p 199.

5. Kanai et al (1957). Measurement of Microtremors II - VII. Bull. Eq. Res. Inst. Tokyo Univ., Vol. 35, pp 109-200. (Series of 6 papers in Japanese, but with English Abstracts).

6. Carder and Gilmore (1945). Ground Vibrations. Bull. Seism. Soc. of America, Vol. 35, p 13.

7. Patterson W.D. (1940). Determination of Ground Periods. Bull. Seism. Soc. of America. Vol. 30, p 129.

8. Aki K. (1957). Space and Time spectra of Stationary Stochastic Waves with Special Reference to Microtremors. Bull. Eq. Res. Inst., Tokyo Univ., Vol. 35, p 415.

9. Akamutu K. (196I). On Microseisms in the Frequency Range from 1 to $200 \mathrm{~Hz}$. Bull. Eq. Res. Inst., Vol. 39, p 23.

10. Kawasumi H. and Shima E. (1965). Some Applications of a Correlator to Engineering Problems. Proc. 3rd World Conf. on Eq. Eng., Vol. 1, p II - 298.

11. Adams R.D. and Orr R. H. (1970). Microseismic Noise Survey in Wellington City. Report No. 60, Geophysics Divn., D.S.I.R.

12. Hatherton $T$. and Orr R.H. (1971). Seismic Noise Survey of Gisborne City. Report No. 63, Geophysics Divn., D.S.I.R.

13. Salt P.E. (1969). Microtremor Studies. M.E. Thesis, Univ, of Auckland.

14. Dibble R.R. (1964). A Portable Slow Motion Tape Recorder for Geophysical purposes. N.Z. Journal of Geology and Geophysics, Vol. $7, p 445$.

15. Parton, I.M. (1972). Site Response to Earthquakes, with Reference to the Application of Microtremor Measurements. Ph.D. Thesis, Univ. of Auckland. 


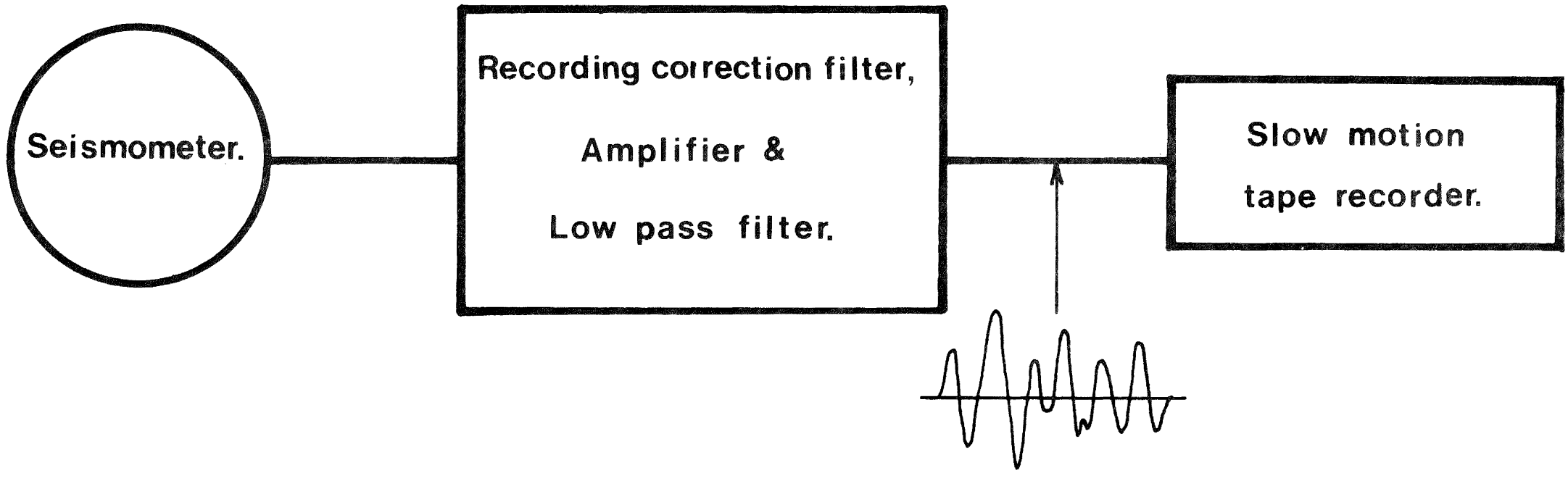

Figure 1: SCHEMATIC RECORDING DIAGRAM Direct Recording Method.

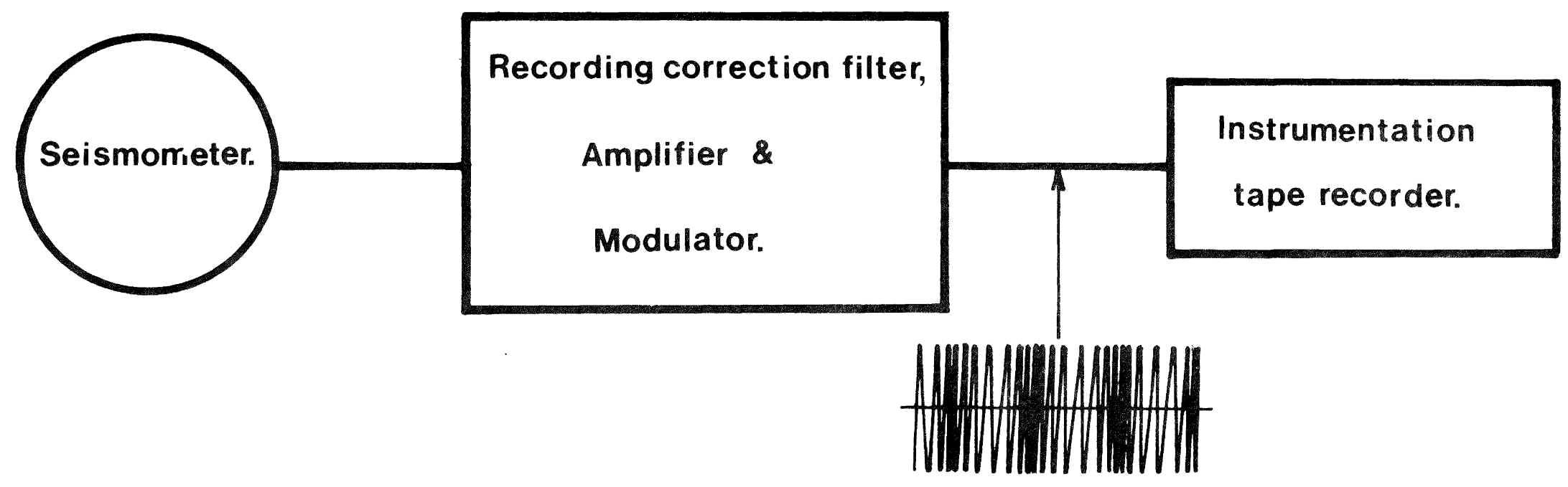




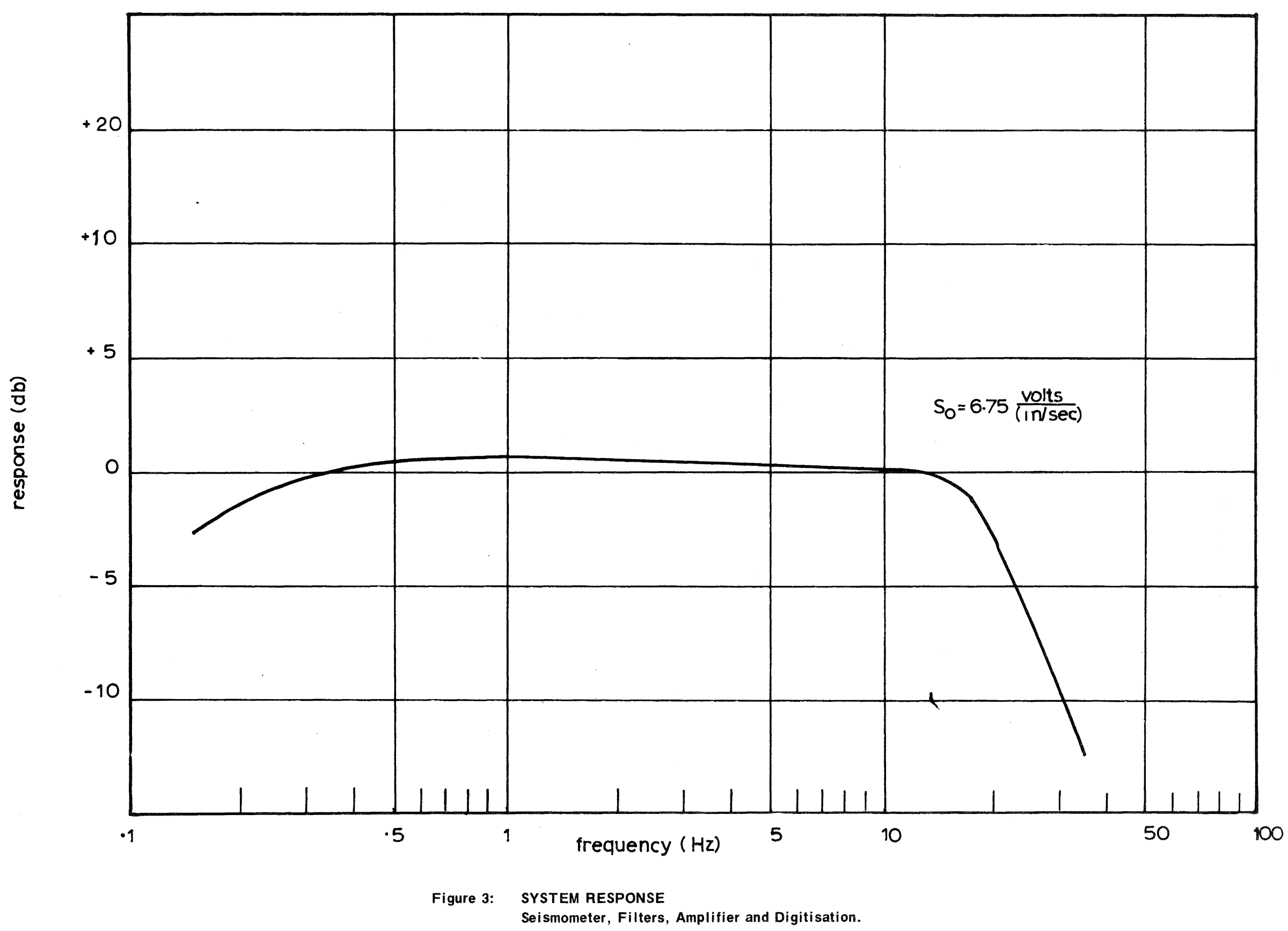

